\title{
Application of Fuzzy Logic and Statistical Approaches for Estimation of Suspended Sediment Concentration
}

\author{
Shreya Nivesh ${ }^{1 *}$, Pravendra Kumar ${ }^{1}$, Pragati Sawant ${ }^{2}$ and Ramesh Verma ${ }^{3}$ \\ ${ }^{1}$ Department of Soil and Water Conservation Engineering, College of Technology, Govind \\ Ballabh Pant University of Agriculture and Technology, Pantnagar-263145, \\ Uttarakhand, India \\ ${ }^{2}$ Department of Soil and Water Conservation Engineering, Dr. A. S. College of Agricultural \\ Engineering and Technology, Mahatma Phule Krishi Vidyapeeth, Rahuri, \\ Ahmednagar- 413722, Maharashtra, India \\ ${ }^{3}$ Department of Soil and Water Conservation Engineering, Institute of Agricultural Sciences, \\ Banaras Hindu University, Varanasi-221005, Uttar Pradesh, India \\ *Corresponding author
}

\begin{tabular}{|l|}
\hline Ke y w o r d s \\
Fuzzy Logic; Multiple \\
Linear Regression; \\
$\begin{array}{l}\text { Sediment Rating } \\
\text { Curve; Calibration; } \\
\text { Validation }\end{array}$ \\
\hline Article Info \\
\hline $\begin{array}{l}\text { Accepted: } \\
\text { 25 January 2018 } \\
\text { Available Online: } \\
\text { 10 February } 2018\end{array}$ \\
\hline
\end{tabular}

\section{Introduction}

Conservation of land and water resources is
among the most important issues related to the
watershed management. Spatially and

Conservation of land and water resources is
among the most important issues related to the
watershed management. Spatially and

Conservation of land and water resources is
among the most important issues related to the
watershed management. Spatially and

\section{A B S T R A C T}

The accelerated erosion and the sediment outflow from agricultural lands is a serious global problem. Mankind will be facing great challenges in the next few decades. The present study was undertaken to estimate the suspended sediment concentration using Fuzzy Logic (FL), Multiple Linear Regression (MLR) and Sediment Rating Curve (SRC) models for the Vamsadhara river catchment comprising of $7820 \mathrm{~km}^{2}$ Area, situated between Mahanadi and Godavari river basins in south India. The perfect input of FL, MLR and SRC models was found by the use of Gamma Test (GT). Three different types of performance indicators viz. root mean square error (RMSE), correlation coefficient (r) and coefficient of efficiency (CE) were used to evaluate the accuracy of various models. Based on the performance analysis SRC, MLR and FL models were used for comparison. Comparison of training period length was also made utilizing two different architectures. Daily simulations using inputs with architecture $(3 * 1)$ three years of training and one year of testing (RMSE-104.85 kg/sec, r-0.963 and CE value 87.93\%) performed better than the simulation with architecture $(2 * 2)$ two years of training and two years of testing. The study demonstrates that fuzzy logic model utilizing Gamma Test for input choosing has superior performance for sediment yield estimation in comparison to the conventional models such as MLR and SRC. The results indicated that fuzzy logic can be applied successfully to provide high accuracy and reliability for sediment estimation. temporally unbalanced distribution of water, along with rapid population growth and negative impacts of human activities on the quality of water resources, has created significant problems in hydrological 
management in recent decades (Akhbari and Grigg 2013). Soil erosion by rainfall and runoff is a major threat to productivity of agriculture. Soil erosion is associated with adverse environmental impacts (Clark et al., 1985) and crop productivity loss (Lal, 1995; Pimentel et al., 1995) that makes its understanding important in assessing food security (Daily et al., 1998) and environmental safety (Matson et al., 1997). In India, an estimated 175 Mha of land constituting about $53 \%$ of total geographical area suffers from deleterious effects of soil erosion (Reddy, 1999). Therefore, a major challenge still remaining is the simulation of processes like runoff and transport of sediment from watersheds. One viable approach to this challenge is the use of suitable hydrological models for efficient management of watersheds and ecosystems (Verma et al., 2010). Hydrologic simulation models are rapidly being improved with increased advances in computer techniques that facilitate their capability to interface with emerging technologies to provide more powerful tools for operational applications. The sediment rating curve is a relationship between the discharge of river and sediment load. Practically a rating curve can be constructed by log-transforming the data and using a linear least squares regression to determine the best fit line. Multiple linear regression (MLR) is a statistics based technique that uses several independent variables to predict the outcome of a dependent variable. MLR takes a group of variables selected randomly and tries to find a linear relationship among them. In recent years, regression models have been successfully employed in modelling a wide range of hydrologic processes like soil temperature (Bilgili, 2010; Tabari et al., 2010; Marofi et al., 2011); flood flows (Engeland and Hisdal, 2009; Eslamian et al., 2010); and sediment prediction (Wang and Linker, 2008; Chang, et al., 2008). Soft computing techniques such as artificial neural networks and adaptive neuro-fuzzy inference system and fuzzy logic are becoming a strong tool for providing environmental, irrigation and drainage, soil and water conservation, and civil engineers with sufficient details for design purposes and management works. Fuzzy logic is an approach to computing based on "degrees of truth" rather than the usual "true or false" (1 or 0$)$. Fuzzy logic is a convenient way to map an input space to an output space. Soft computing techniques such as ANNs, ANFIS and fuzzy logic including time series prediction of runoff or discharge (Bonafe et al., 1994; Hsu et al., 1995; Shamseldin, 1997; Zealand et al., 1999; Elshorbagy et al., 2005; Jain, 2001; Agarwal et al., 2003; Melesse and Wang, 2006; Elshafie, 2011; Chakravati et al., 2015; Noori and Kalin, 2016); sediment prediction (Abrahart and white, 2001; Yitian and $\mathrm{Gu}$, 2003; Alp and Cigizoglu, 2007; Dehgani, 2009; Shabani et al., 2012; Olyaie, 2015; Buyukyildiz and Kumcu, 2017).

Fuzzy Logic (FL) modeling refers to process whereby dynamical system is modeled not in the form of conventional differential and difference equations but in the form of set of fuzzy rules and corresponding membership function. Fuzzy logic has been used successfully for the planning and management of watersheds (Kothari, 1987). Mishra \& Kothari (1989) used a general methodology for fuzzy regression and illustrated it by actual hydrological case study. Mitra et al., (1998) proposed two fuzzy logic models that predict soil erosion in a relatively large watershed using a limited number of input variables. They reported that two variables fuzzy logic model had similar percentage of the area in the watershed as the Universal Soil Loss Equation (USLE) model in all erosion categories whereas, three variables model predicted similar percentage of the area as the USLE model only in the low soil erosion category. Matarazzo \& Munda (2001) suggested a 
methodology to compare fuzzy numbers in which the case of L-R fuzzy numbers was considered, requiring no normalization of fuzzy number. Hollert et al., (2002) Compared different statistical methods (ranking, cluster analyses, Hasse diagram techniques, and fuzzy logic) for the evaluation and presentation of the data with respect to the needs of environmental decision-making. Tran et al., (2002) studied fuzzy logic based modeling to improve the performance of the Revised Universal Soil Loss Equation (RUSLE). Tayfur et al., (2003) proposed fuzzy algorithm to estimate sediment loads from bare soil surfaces utilizing the rainfall intensity and slope data. Kisi (2004) presented the application of evolutionary fuzzy models (EFM) for suspended sediment concentration estimation. The evolutionary fuzzy models (EFMs) were improved by the combination of two methods, fuzzy logic and differential evolution. Based on comparison of results it was found that evolutionary fuzzy models (EFMs) were better than other methods. Kisi et al., (2006) proposed a fuzzy logic approach to estimate suspended sediment concentration from stream flow. Lohani et al., (2007) developed fuzzy logic technique to model the stage-discharge-sediment concentration relationship. Samani et al., (2011) used an approach of fuzzy logic and neural network to estimate long-shore sediment transport rate (LSTR). Comparison of fuzzy logic and artificial neural network (ANN) models with the conventional methods showed high performance and more accuracy in predicting the long-shore sediment transport rate (LSTR). Sundara Kumar et al., (2015) studied runoff and sediment yield prediction for a reservoir basin viz. Megadrigedda reservoir situated in Visakhapatnam district, Andhra Pradesh. Oinam et al., (2014) proposed a fuzzy rule base approach for developing soil a protection index map: a case study in the upper awash basin, Ethopian highlands. Wang et al., (2015) used fuzzy intelligence system for land consolidation-a case study for Shunde, China. Kisi (2016) developed a new approach for modeling suspended sediment using evolutionary fuzzy approach. Vercruysse et al., (2017) studied suspended sediment transport dynamics in rivers: multi-scale driver of temporal variation.

Keeping the above views in mind, the present study has been undertaken with the following objectives:

Development of the models using fuzzy logic (FL), multiple linear regression (MLR) and sediment rating curve (SRC) to estimate the daily suspended sediment concentration.

Validation of the formulated models.

Performance evaluation of the developed models for Vamsadhara river catchment.

Comparison of the FL, MLR and SRC models.

\section{Materials and Methods}

\section{Study Area}

The study was conducted in Vamsadhara river basin comprising of $7820 \mathrm{~km}^{2}$, situated within the geographical coordinates of $18^{\circ} 15^{\prime}$ to $19^{\circ}$ $55^{\prime} \mathrm{N}$ latitudes and $83^{\circ} 15^{\prime}$ to $84^{\circ} 20^{\prime} \mathrm{E}$ longitudes in between Mahanadi and Godavari river basins falls in the state of Orissa and the rest $26 \%$ in Andhra Pradesh. Hydrological data were collected by India Meteorological Department (IMD) and Central Water Commission (CWC), Godavari Mahanadi Circle Division, South Eastern Region, Bhubaneswar, Orissa at six sites: Kutraguda, Mohana, Gudari, Mohandragarh, Gunpur, and Kashinagar. The measurements include rainfall in the units of millimeters, discharge in the units of $\mathrm{m}^{3} / \mathrm{sec}$ and sediment concentration in the units of $\mathrm{kg} / \mathrm{m}^{3}$. The daily weighted rainfall for the study area was found 
by considering the Theissen polygons. The location map of the study area is shown in Fig. 1 .

\section{Methodologies}

\section{Fuzzy Logic approach}

Fuzzy means not clear, distinct, or precise; blurred. The idea of fuzzy logic was given by Zadeh (1965), a computer scientist of the University of California at Berkeley. It is a convenient way to map an input space to an output space. Fuzzy logic is a powerful problem solving methodology with a myriad of applications in embedded control and information processing. Fuzzy logic provides a remarkably simple way to draw definite conclusion from vague, ambiguous or imprecise information.

Fuzzy logic resembles human decision making with its ability to work from approximate data and find precise solutions. Fuzzy Logic (FL) modeling refers to process whereby dynamical system is modeled not in the form of conventional differential and difference equations but in the form of set of fuzzy rules and corresponding membership function.

Therefore, it is often called "fuzzy expert system. Fuzzy logic has been gaining increasing acceptance during the past few years. There are over two thousand commercially available products using fuzzy logic ranging from washing machines to high speed trains. The general fuzzy system is represented in Fig. 2 has the components of fuzzification, rule evaluation, aggregation of the rule outputs and defuzzification.

\section{Fuzzification}

Fuzzification takes the crisp inputs and determines the degree to which these inputs belong to each of the appropriate fuzzy sets.

\section{Rule evaluation}

It takes the fuzzified inputs and applies them to the antecedents of the fuzzy rules. If a given fuzzy rule has multiple antecedents, the operator (AND or OR) is used to obtain a single number that represents the result of antecedent evaluation.

\section{Aggregation of the rule outputs}

Aggregation is the process of unification of the outputs of all rules. It takes the membership functions of all rule consequent previously clipped or scaled and combine them into a single fuzzy set.

\section{Defuzzification}

The last step in the fuzzy inference system is the defuzzification. Fuzziness helps us to evaluate the rules, but the final output of a fuzzy system has to be a crisp number.

There are several defuzzification methods, but probably the most popular one is the centroid technique. It finds the point where a vertical line would slice the aggregate set into two equal masses.

\section{Multiple Linear Regression}

Regression analysis is used when two or more variables are thought to be well connected by a linear relationship systematically. MLR applies to problems in which records have been kept of one variable, $y$, the dependent variable, and several other variables $\mathrm{x}_{1}, \ldots, \mathrm{x}_{\mathrm{k}}$, the independent variables, and in which the objective requires the relationship between the variable $y$ and the variables $\mathrm{x}_{1}, \ldots, \mathrm{x}_{\mathrm{k}}$ to be investigated. In the present study the multiple linear regressions analysis was performed on the same data set to estimate sediment concentration and the regression equation used is defined as 
$\mathrm{S}_{\mathrm{t}}=\mathrm{a}+\mathrm{bP}_{\mathrm{t}}+\mathrm{cQ}_{\mathrm{t}}$

Where a, b, c, d and e are constants and $\mathrm{P}_{\mathrm{t}}, \mathrm{Q}_{\mathrm{t}}$, $\mathrm{Q}_{\mathrm{t}-1}$, and $\mathrm{S}_{\mathrm{t}-1}$ are the variables.

\section{Sediment Rating Curve}

The sediment rating curve is a relationship between the river discharge and suspended sediment load. Such curves are widely used to estimate the sediment load being transported by river. In this study sediment rating curve was developed for Vamsadhara River basin using daily data of stream flow and suspended sediment concentration. The relationship between the sediment concentration or load $\mathrm{S}_{\mathrm{t}}$ and discharge $\mathrm{Q}_{t}$ is of the following form

$\mathrm{S}_{\mathrm{t}}=\mathrm{aQ}_{\mathrm{t}}^{\mathrm{b}}$

Where $\mathrm{a}$ and $\mathrm{b}$ are regression constants, $\mathrm{Q}_{\mathrm{t}}$ is discharge and $S_{t}$ is suspended sediment load at time $\mathrm{t}$.

\section{Model Development}

For the present study four years daily data of rainfall, stream flow and sediment concentration of monsoon season from June 1, 1997 to October 31, 2000 was used. The total data of monsoon season were divided into two sets. (1) Daily simulation using inputs with architecture $2 * 2$ (two years of training and two years of testing). (2) Daily simulations with architecture $3 * 1$ (three years of training and one year of testing). MATLAB (R2009a) software was used to model suspended sediment load. GT was used for identifying the best input combination of input variables. Different combinations of input variables were explored to assess their influence on the sediment prediction as represented in Table 1 . Gamma test predicts the minimum achievable modeling error before the modeling. To determine the best input combination in modeling, various combinations of input parameters were assessed using GT so as to identify the most appropriate combination among the remained variables to predict the sediment concentration. The results showed that the best input combination of the variable is when using $\mathrm{P}_{\mathrm{t}}, \mathrm{P}_{\mathrm{t}-1}, \mathrm{Q}_{\mathrm{t}}, \mathrm{Q}_{\mathrm{t}-1}$ and $\mathrm{Q}_{\mathrm{t}-2}$. Based on minimum values of gamma test $(\Gamma)$, standard error and V-ratio the model employed for the present study consists of $P_{t}$, $\mathrm{Q}_{\mathrm{t}}$, as inputs to the model to predict $\mathrm{S}_{\mathrm{t}}$ shown in Table 2.

The fuzzy logic based models were formulated to estimate the suspended sediment concentration from Vamsadhara river basin. Considering the experimental data into consideration rainfall, streamflow and sediment concentration were fuzzified into fuzzy subsets in order to cover the whole range of changes during training period. The maximum rainfall is considered as 126.3036 $\mathrm{mm}$ and its subdivision into three subsets as Low (L), Medium (M) and High $(\mathrm{H})$ is considered to have triangular member ship function as represented in Fig. 3.

Similarly discharge is considered to have maximum value of $2069.8 \mathrm{~m}^{3} / \mathrm{sec}$ and its subdivision into six subsets as Very Low (VL), Low (L), Medium (M), High (H), Very High ( $\mathrm{VH})$ and Exceptional High (EH) is considered to have triangular membership function as represented in Fig. 4.

Finally sediment concentration is considered to have maximum value of $7710.2 \mathrm{~kg} / \mathrm{m}^{3}$ and its subdivision into nine subsets as Exceptional Low (EL), Very Low (VL), Low (L), Quite Low (QL), Medium (M), Quite High $(\mathrm{QH})$, High $(\mathrm{H})$, Very High $(\mathrm{VH})$ and Exceptional High (EH) is considered to have triangular membership function as represented in Fig. 5.

For the present study fuzzy rule base relating rainfall, discharge and sediment concentration 
were constructed from the experimental data. The former part of the rule (the part beginning with IF, up to THEN) included a statement on the rainfall and runoff while the later part (the part beginning with THEN, up to end) included a statement on sediment concentration. Table 3 summarizes the fuzzy rules constructed in this study.

\section{Model Performance}

Three statistical measures were used to examine the goodness to fit of the FL, MLR and SRC models to the testing data.

These measures include the root mean square error (RMSE), correlation coefficient (r) and coefficient of efficiency (CE).

\section{Root mean square error (RMSE)}

It yields the residual error in terms of the mean square error expressed as:

$$
R M S E=\sqrt{\frac{\sum_{i=1}^{n}\left(S_{o, i}-S_{e, i}\right)^{2}}{N}}
$$

\section{Correlation coefficient (r)}

It is a measure of how well the estimated values from an estimated model fit with the real-life data. It is expressed as:

$$
r=\frac{\sum_{i}^{N}\left(\left(S_{o, i}-\bar{S}_{o, i}\right)\left(S_{e, i}-\bar{S}_{e, i}\right)\right)}{\sqrt{\sum_{i}^{N}\left(S_{o, i}-\bar{S}_{o, i}\right)^{2} \sum_{i}^{N}\left(S_{e, i}-\bar{S}_{e, i}\right)^{2}}}
$$

\section{Coefficient of efficiency (CE)}

The Nash-Sutcliffe model efficiency coefficient is used to assess the predictive power of hydrological models and is expressed as:
$C E=\left\{1-\frac{\sum_{i}^{N}\left(S_{o, i}-S_{e, i}\right)^{2}}{\sum_{i}^{N}\left(S_{o, i}-\bar{S}_{o, i}\right)^{2}}\right\} * 100$

Where, $S_{o, i}$ and $S_{e, i}$ are the observed and estimated suspended sediment concentration; and are the average observed and estimated suspended sediment concentration respectively for the $i^{\text {th }}$ data set and $\mathrm{N}$ is the total number of observations.

\section{Results and Discussion}

Performances of the developed models were evaluated qualitatively and quantitatively by visual observation and employing various statistical and hydrological indices viz. correlation coefficient (r), root mean square error (RMSE) and coefficient of efficiency (CE). The best model is selected based on lower value of root mean square error and higher values of correlation coefficient and coefficient of efficiency. Various statistical performance evaluation indices of the models are shown in the Tables 4, 5 and 6.

\section{Fuzzy Logic (FL) sediment model}

The fuzzy logic based models were formulated to estimate the suspended sediment concentration using triangular membership functions, considering different number of membership functions per input and output variables. The fuzzy rule base was created on the basis of historical data and intuition. The centroid method of defuzzification was adopted to obtain crisp output value. The fuzzy models were developed for the study watershed under fuzzy logic toolbox in MATLAB (R2009a). As seen from the Tables 4 and 5 the value of RMSE for the architectures $2 * 2$ and $3 * 1$ are $109.407 \mathrm{~kg} / \mathrm{sec}$ and $104.852 \mathrm{~kg} / \mathrm{sec}$ respectively. The correlation coefficient (r) are 0.954 and 0.963 
while, the coefficient of efficiency (CE) are $87.576 \%$ and $87.932 \%$ respectively. The tables show that fuzzy logic results are much closer to the observed values.

\section{Multiple Linear Regression sediment model}

(MLR)

From the Tables 4 and 5 it has been found that for the two architectures the RMSE values in case of MLR models are $226.339 \mathrm{~kg} / \mathrm{sec}$ and $180.344 \mathrm{~kg} / \mathrm{sec}$ respectively. The correlation coefficient are 0.801 and 0.872 whereas, the coefficient of efficiency are $46.828 \%$ and $64.30 \%$. Poor CE value in case of $2 * 2$ clearly shows that regression analysis cannot be applied in this catchment for estimating the sediment yield considering $50 \%$ data for training period and $50 \%$ for testing period.

\section{Sediment Rating Curve (SRC) sediment model}

As revealed from the Tables 4 and 5 the values of performance evaluation indices viz. RMSE, $r$ and CE for sediment rating curve model which takes concurrent runoff as input does not produce satisfactory results. The RMSE values for the two architectures are $233.899 \mathrm{~kg} / \mathrm{sec}$ and $192.464 \mathrm{~kg} / \mathrm{sec}$; $\mathrm{r}$ values are 0.673 and 0.828 on the other hands, CE values are $43.216 \%$ and $59.340 \%$ respectively.

\section{Comparison of FL, MLR and SRC models}

The models were evaluated qualitatively and quantitatively by visual observation and employing various statistical and hydrological indices. The graphical representations along with corresponding scattered plots for the FL, MLR and SRC models are shown in figures 6 to 11. As observed from the Table 6 fuzzy logic model which takes concurrent rainfall and runoff as inputs and concurrent sediment as output performed better than other models in terms of RMSE, $r$ and CE. In case of fuzzy logic model with architecture $3 * 1$ the RMSE, $r$ and CE values were $104.852 \mathrm{~kg} / \mathrm{sec}, 0.963$ and $87.932 \%$ respectively. While, for $2 * 2$ were $109.407 \mathrm{~kg} / \mathrm{sec}, \quad 0.954$ and $87.576 \%$ respectively. The model results showed that the FL models have the highest efficiency to reproduce the daily suspended load.

The multiple linear regression analysis was performed on the same data set to predict sediment load and results were compared with FL and SRC models. As depicted in Table 2 MLR predicted well the daily suspended sediment for the arrangement $3 * 1$ with RMSE, $\mathrm{r}$ and $\mathrm{CE}$ values $180.344 \mathrm{~kg} / \mathrm{sec}, 0.872$ and $64.30 \%$ respectively. However, the results shown by MLR model in case of $2 * 2$ were less satisfactory with RMSE, $r$ and $\mathrm{CE}$ values $226.339 \mathrm{~kg} / \mathrm{sec}, \quad 0.801$ and $46.828 \%$ respectively. This discrepancy might be due to less data used for calibration or imprecise representation of spatial distribution of rainfall within the watershed by the estimated mean areal rainfall used as an input. In case of SRC with architecture $3 * 1$ the RMSE, $r$ and CE values were $192.464 \mathrm{~kg} / \mathrm{sec}, 0.828$ and 59.34 $\%$ respectively. Whereas, for the architecture $2 * 2$ the RMSE, $\mathrm{r}$ and $\mathrm{CE}$ values for SRC model were $233.899 \mathrm{~kg} / \mathrm{sec}, 0.673$ and 43.216 $\%$ respectively. Comparing observed data and the estimated data through developed fuzzy logic (FL) models, it was found that the developed fuzzy logic (FL) models predict better results than the traditional models, like linear multiple regression and sediment rating curve. A proper watershed management plan can be developed and implemented effectively only when availability and outflow of water and loss of sediment from the watershed can accurately be assessed for future. With this in view, present study has been undertaken to develop fuzzy logic (FL), multiple linear regression (MLR) and sediment rating curve (SRC) models on daily basis for Vamsadhara river catchment. 
Fig.1 Location map of Vamsadhara river basin, India
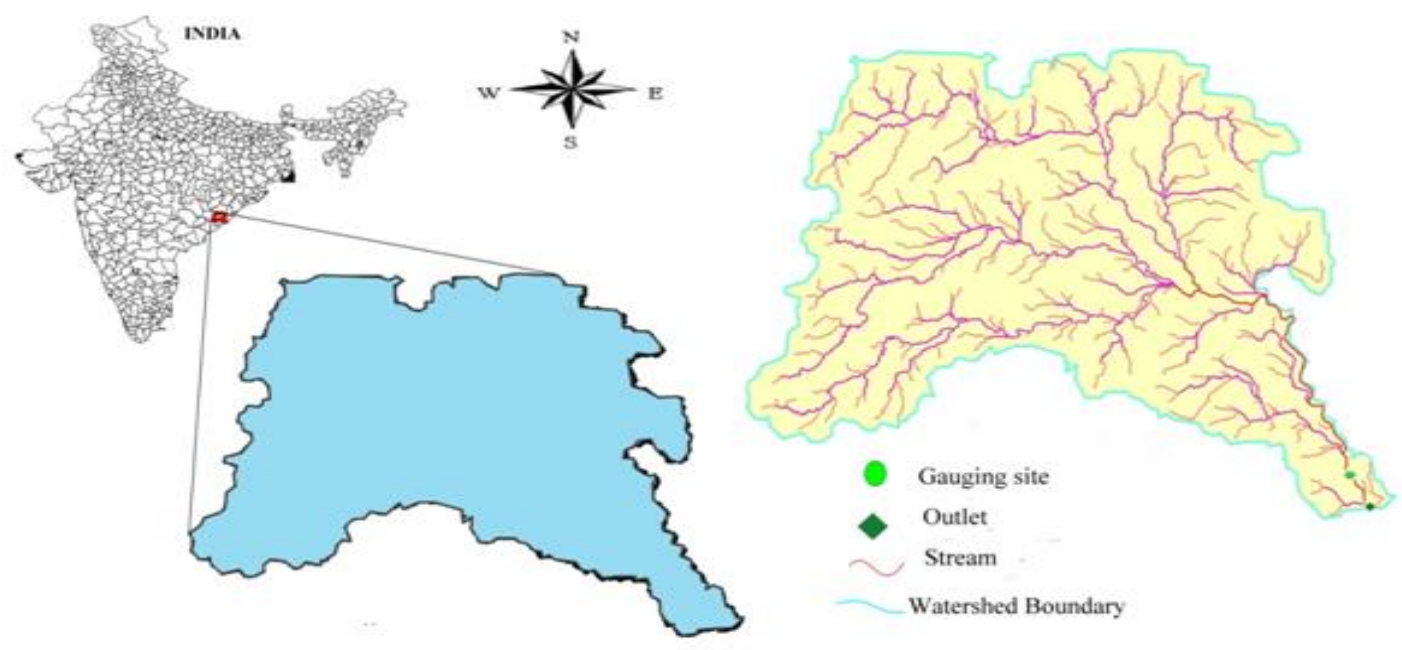

Fig.2 Schematic representation of a fuzzy system

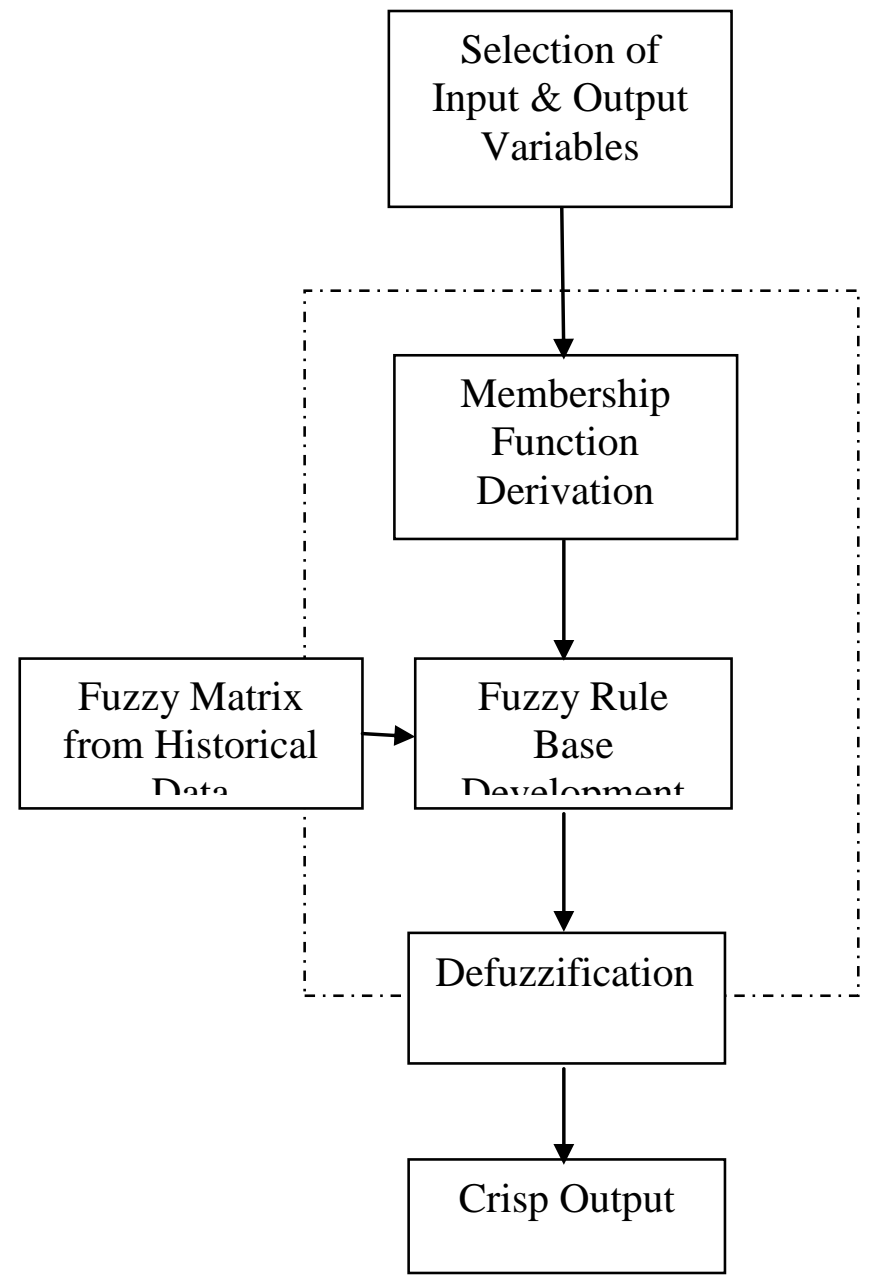


Int.J.Curr.Microbiol.App.Sci (2018) 7(2): 3716-3733

Fig.3 Fuzzy subsets for rainfall

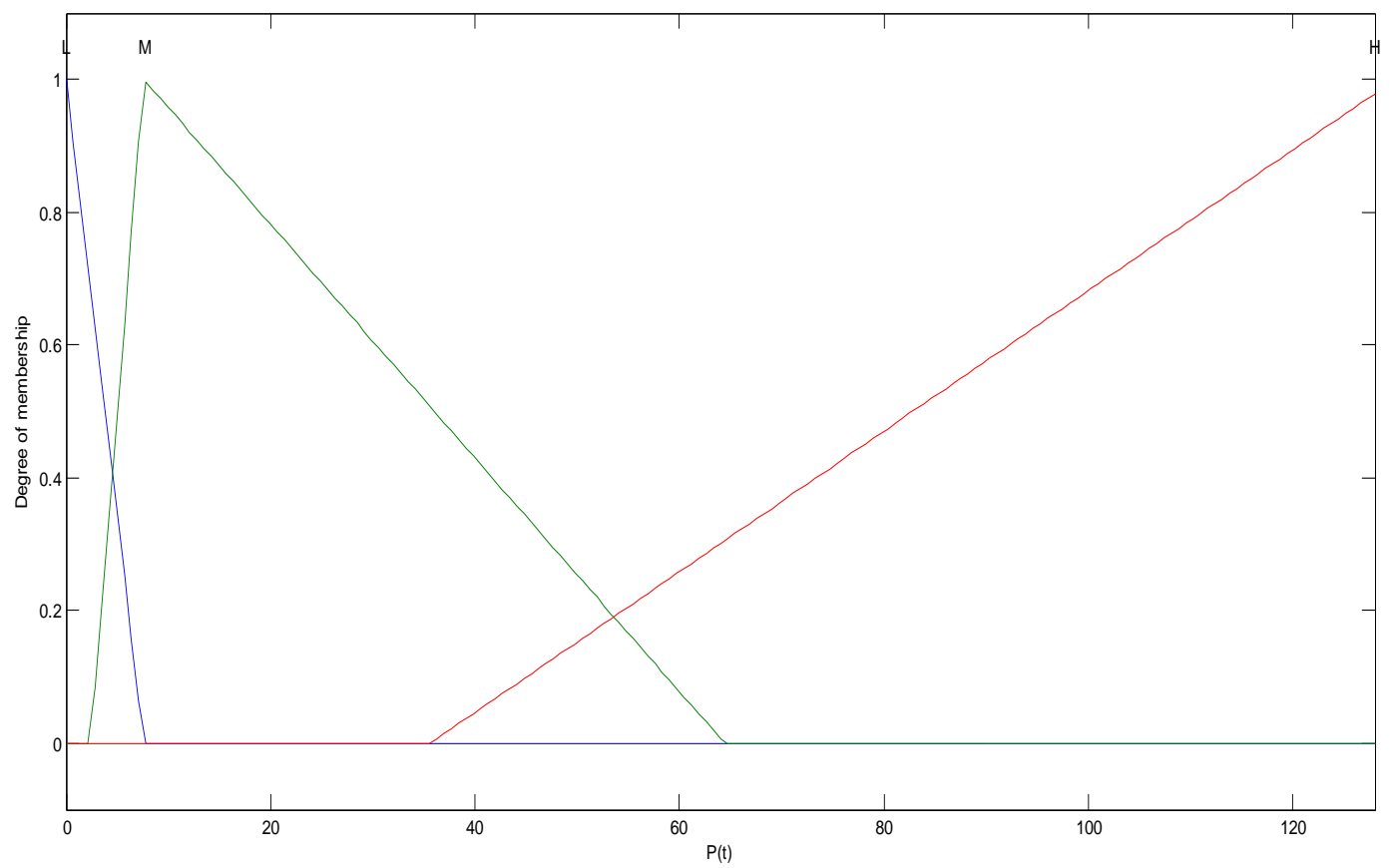

Fig.4 Fuzzy subsets for streamflow

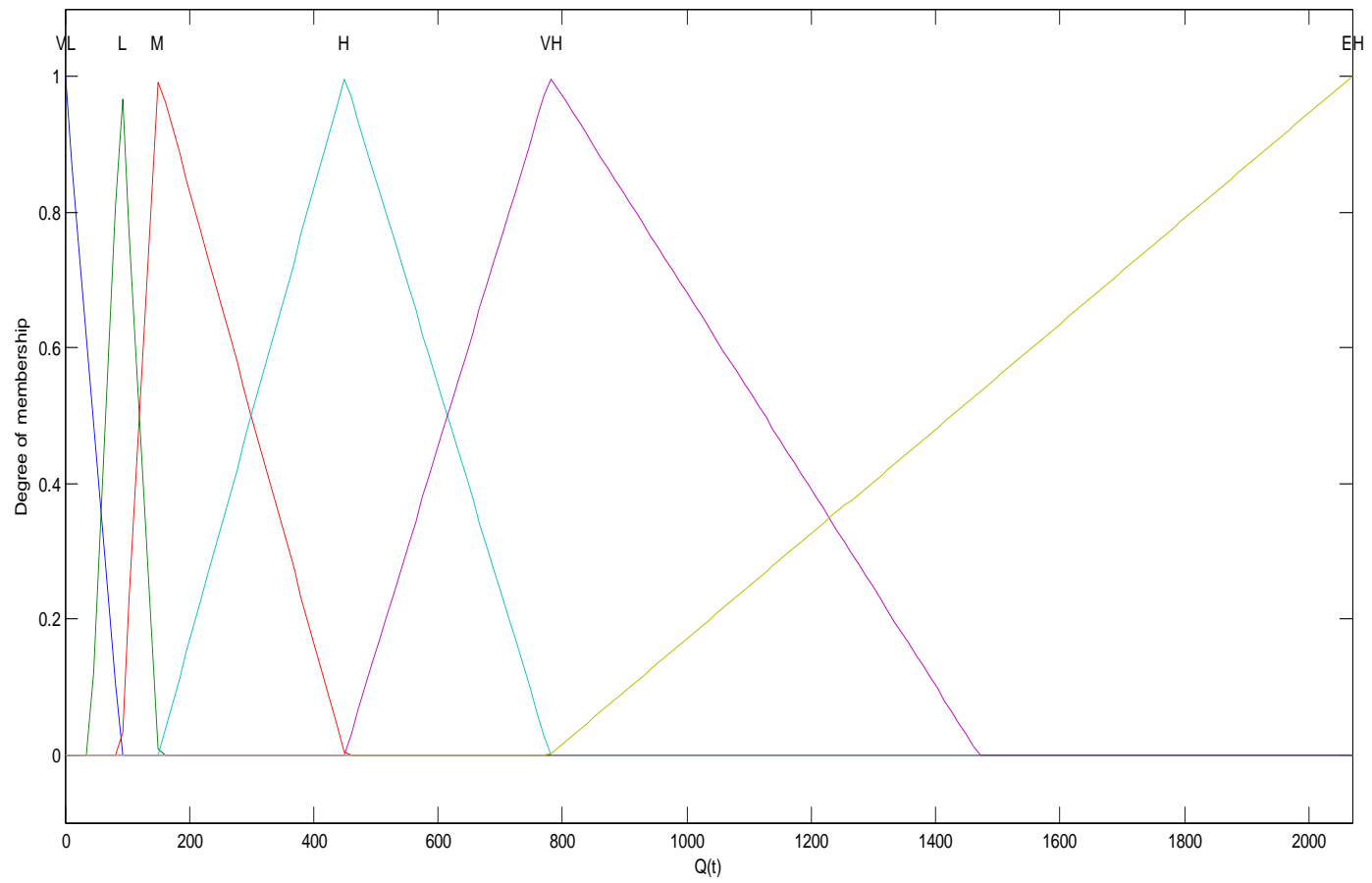


Fig.5 Fuzzy subsets for sediment load

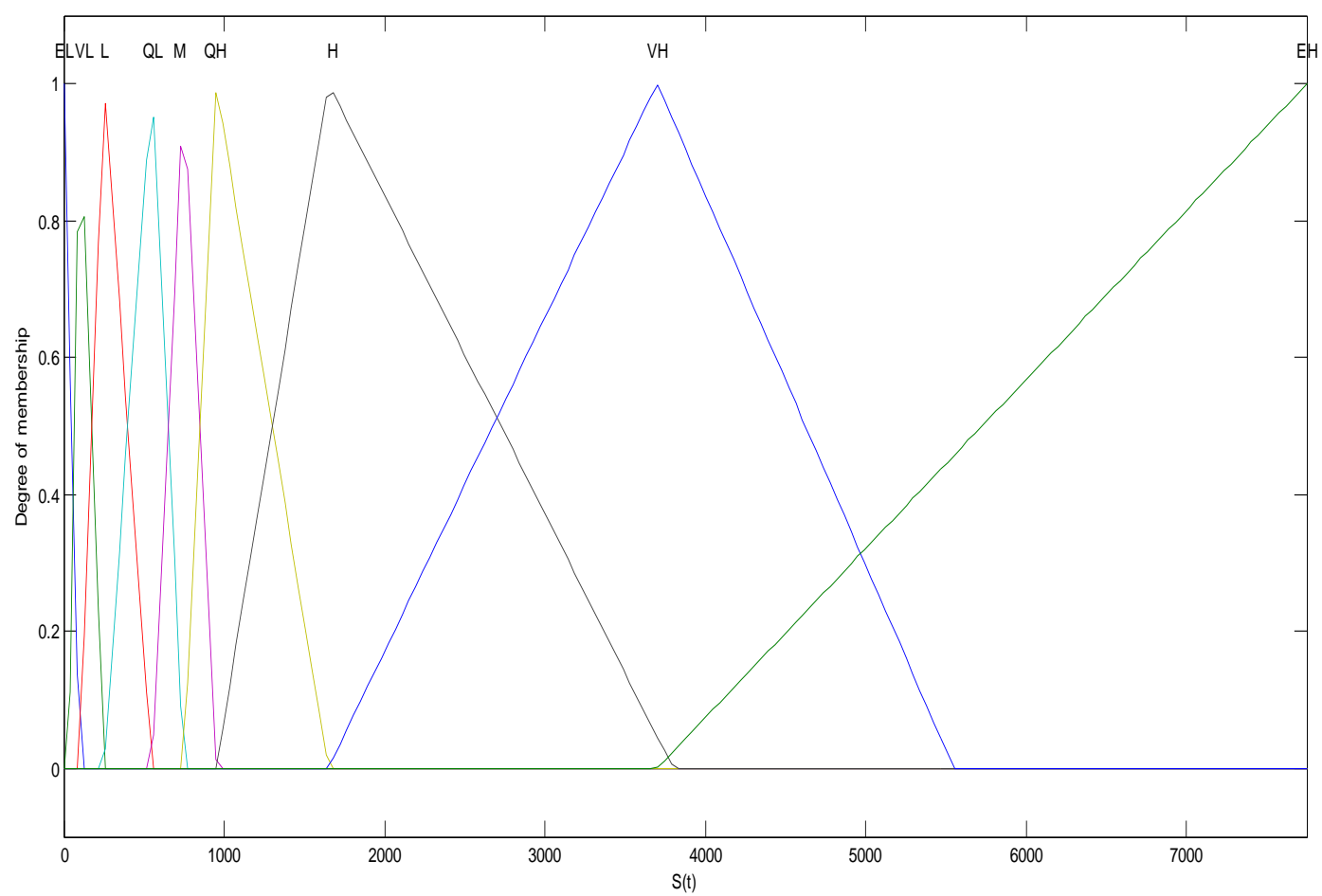

Fig.6 Series and scatter plots of FL model for testing period with architecture $2 * 2$
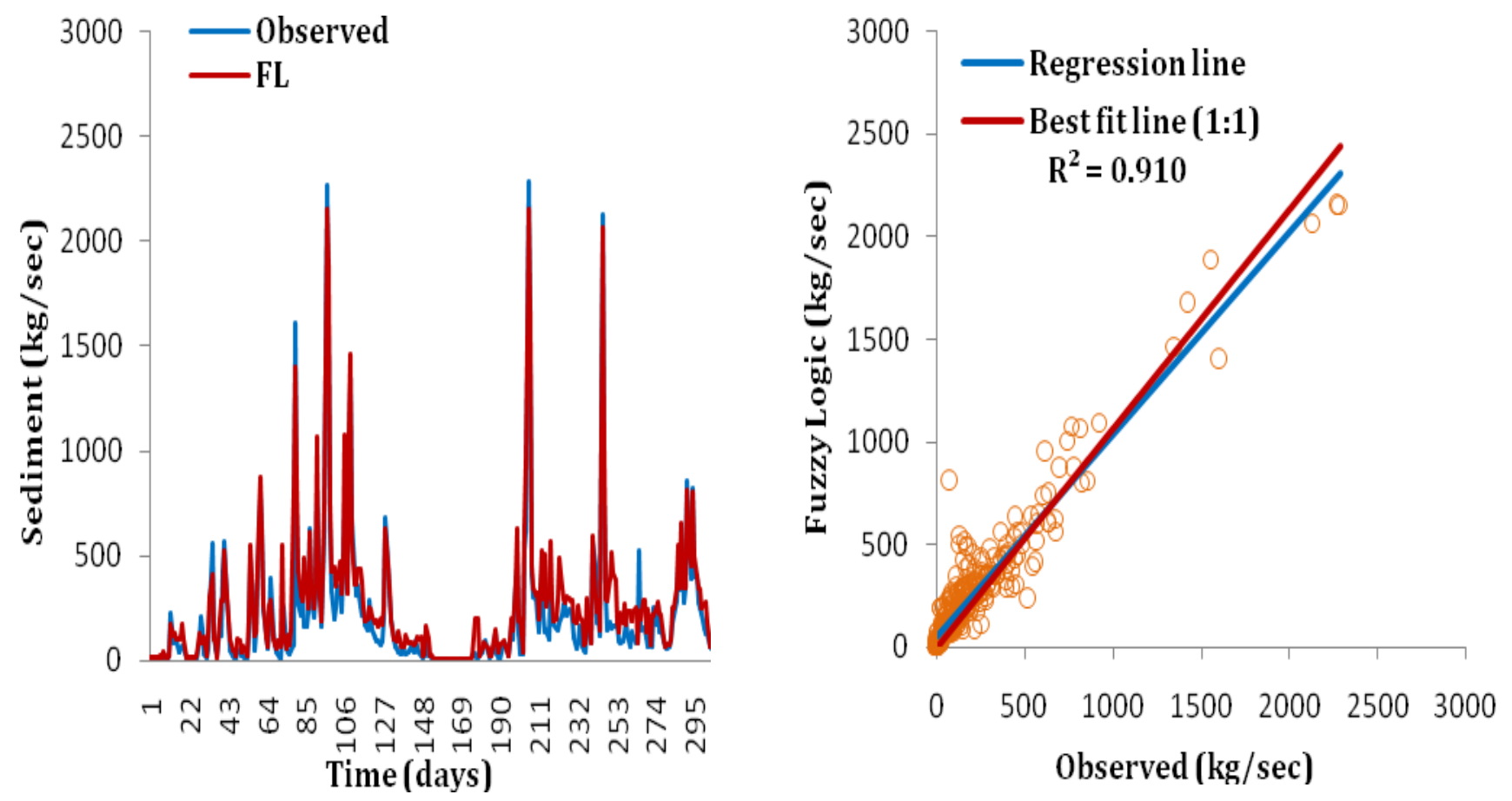
Fig.7 Series and scatter plots of FL model for testing period with architecture $3 * 1$.
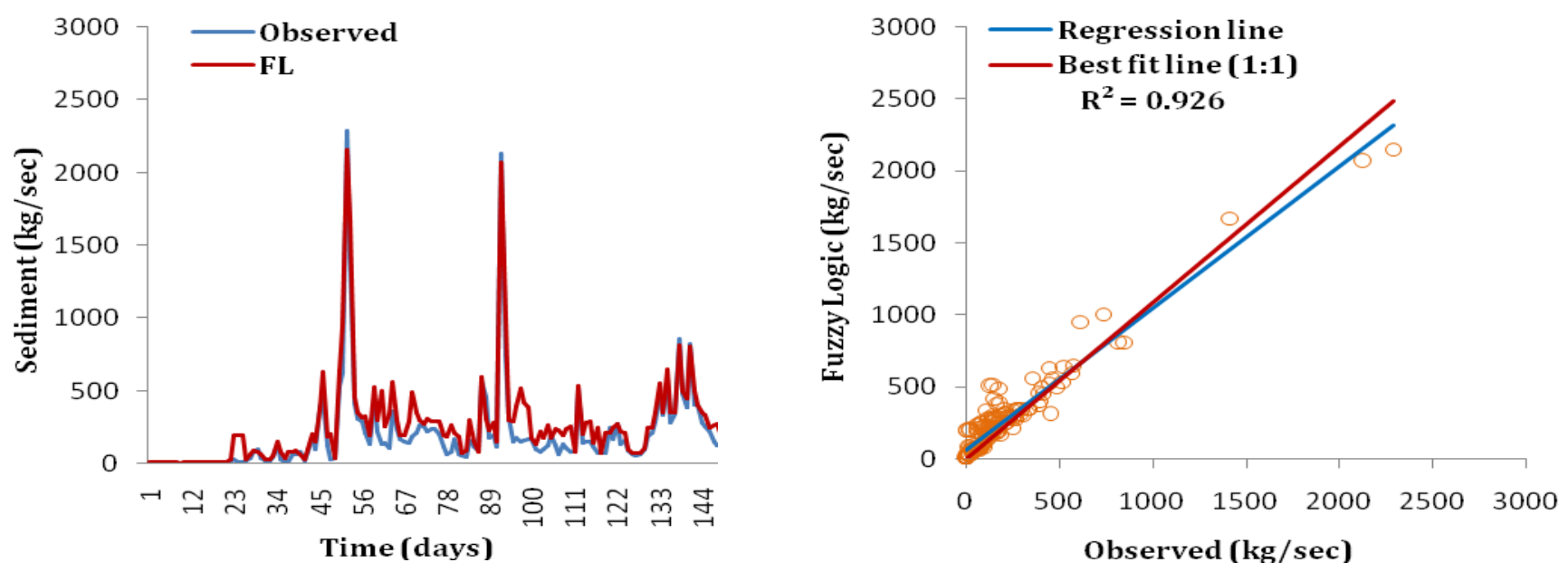

Fig.8 Series and scatter plots of MLR model for testing period with architecture $2 * 2$
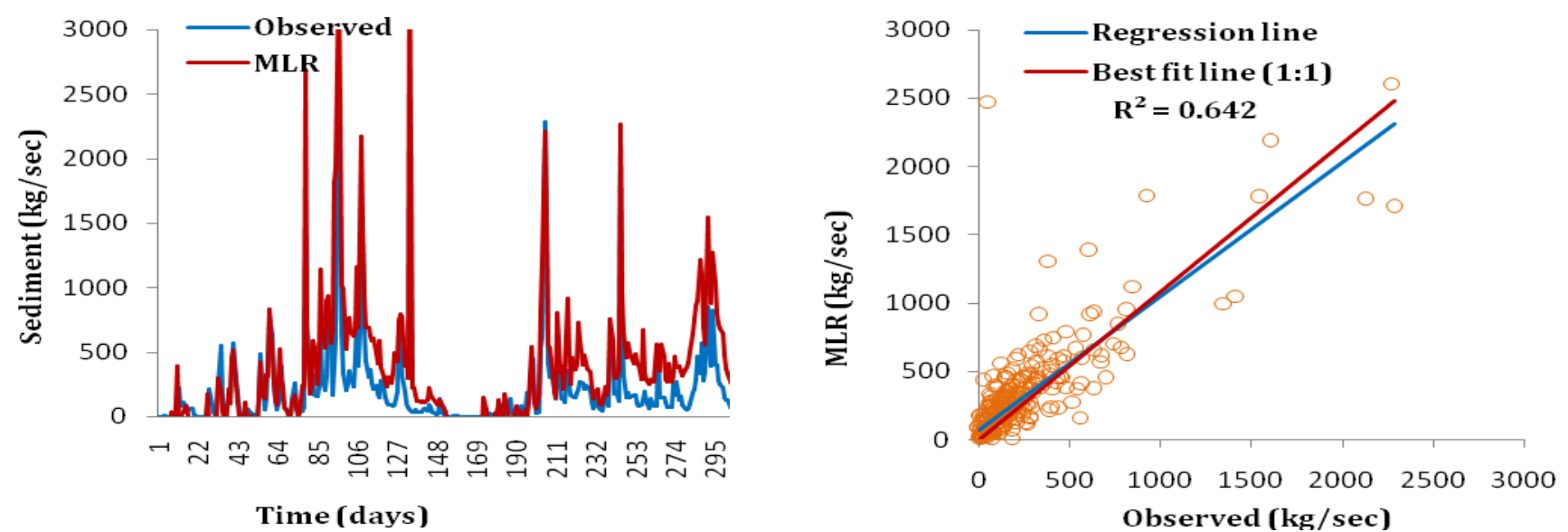

Fig.9 Series and scatter plots of MLR model for testing period with architecture $3 * 1$
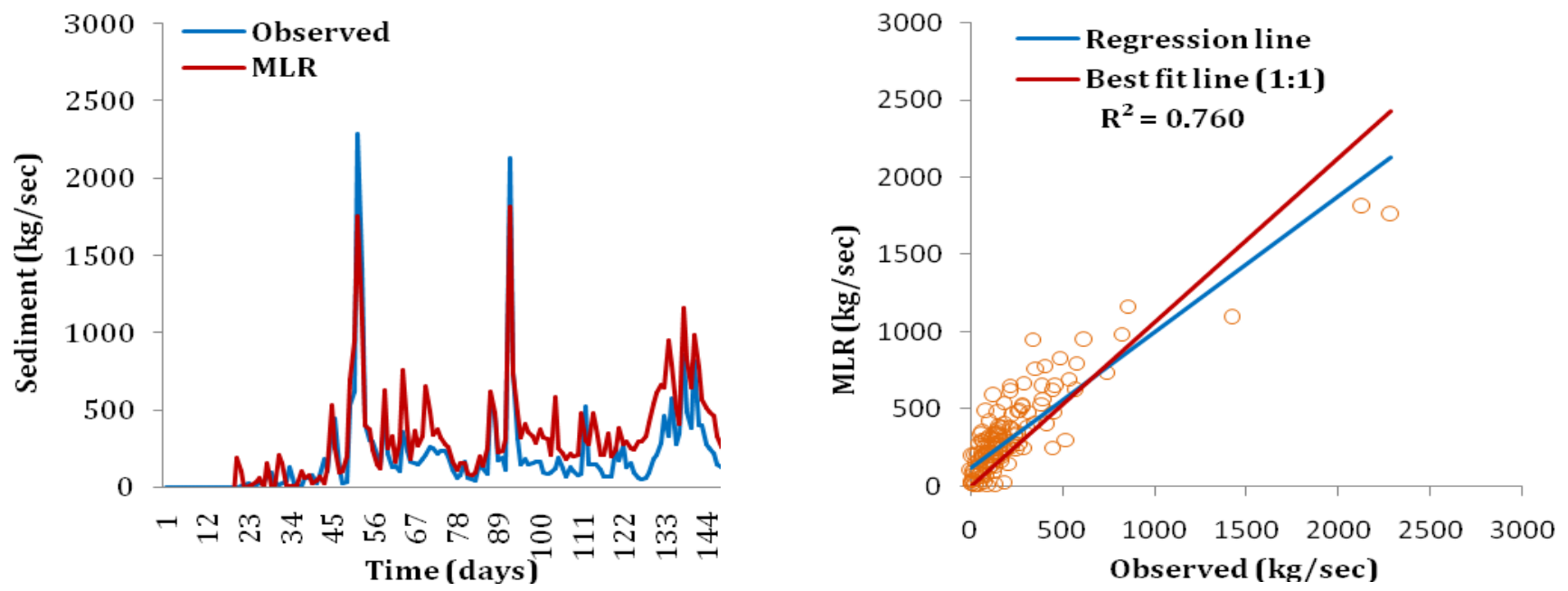
Fig.10 Series and scatter plots of SRC model for testing period with architecture $2 * 2$
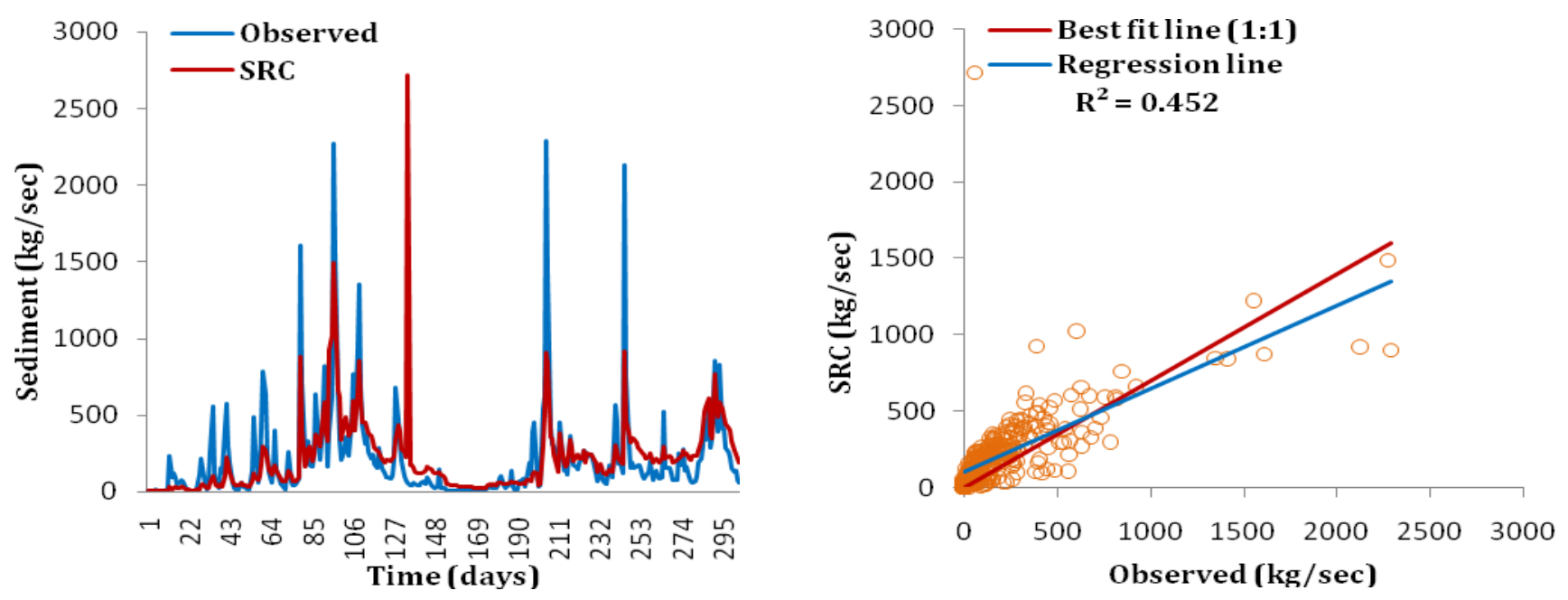

Fig.11 Series and scatter plots of SRC model for testing period with architecture $3 * 1$
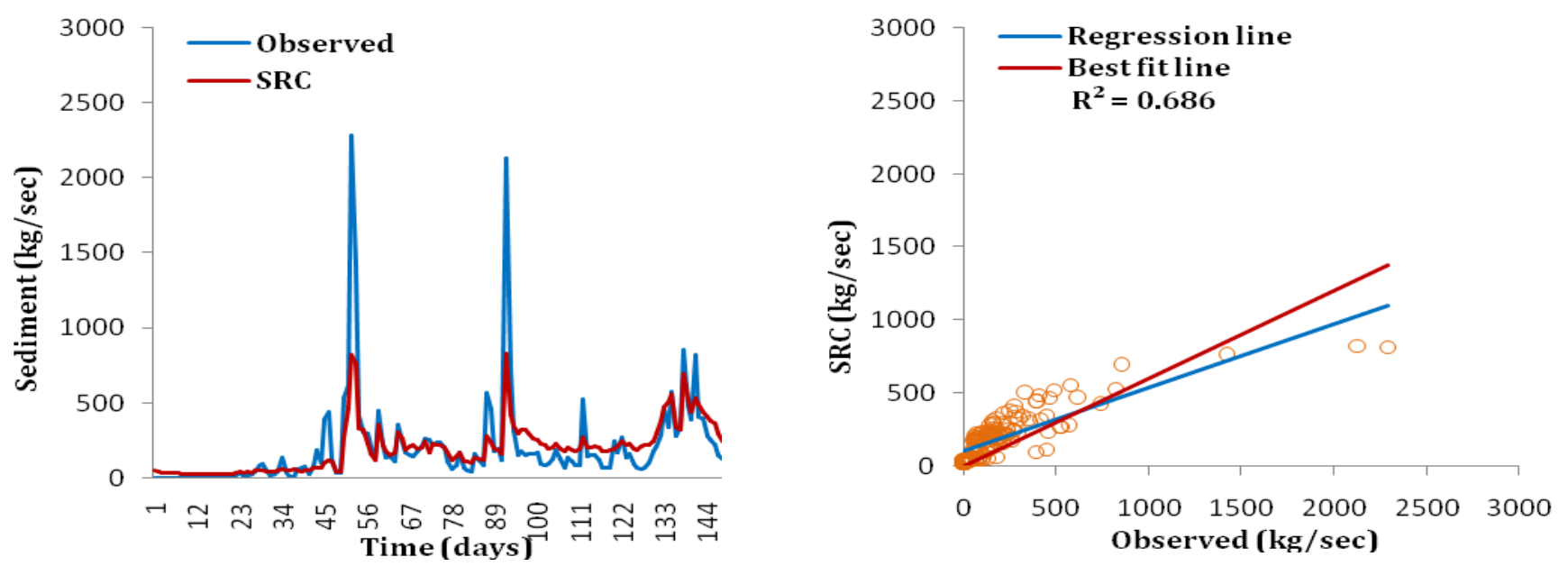

Table.1 Identifying the most effective variable based on Gamma Test

\begin{tabular}{|l|c|l|l|l|}
\multicolumn{1}{c|}{$\begin{array}{c}\text { Different } \\
\text { combinations }\end{array}$} & Mask & Gamma & SE & $\mathrm{V}_{\text {ratio }}$ \\
\hline All & 11111111 & 0.07148 & 0.01020 & 0.18595 \\
\hline $\mathbf{P}_{\mathbf{t}}$ & 01111111 & 0.04830 & 0.01904 & 0.29323 \\
\hline $\mathbf{P}_{\mathbf{t}-\mathbf{1}}$ & 10111111 & 0.06394 & 0.01345 & 0.25578 \\
\hline $\mathbf{P}_{\mathbf{t}-\mathbf{2}}$ & 11011111 & 0.05970 & 0.01199 & 0.23882 \\
\hline $\mathbf{Q}_{\mathbf{t}}$ & 11101111 & 0.07527 & 0.01365 & 0.30109 \\
\hline $\mathbf{Q}_{\mathbf{t}-1}$ & 11110111 & 0.06394 & 0.01201 & 0.25579 \\
\hline $\mathbf{Q}_{\mathbf{t}-2}$ & 11111011 & 0.06363 & 0.01261 & 0.25452 \\
\hline $\mathbf{S}_{\mathbf{t}-1}$ & 11111101 & 0.02225 & 0.01452 & 0.08903 \\
\hline $\mathbf{S}_{\mathbf{t}-2}$ & 11111110 & 0.04336 & 0.00963 & 0.17346 \\
\hline
\end{tabular}


Int.J.Curr.Microbiol.App.Sci (2018) 7(2): 3716-3733

Table.2 Determination of the best combination

\begin{tabular}{|l|l|l|l|l|}
\hline $\begin{array}{l}\text { Different } \\
\text { combinations }\end{array}$ & Mask & Gamma & SE & V ratio \\
\hline $\mathbf{P}_{\mathbf{t}}$ & 10000000 & 0.14760 & 0.02249 & 0.59041 \\
\hline $\mathbf{Q}_{\mathbf{t}}$ & 00010000 & 0.10772 & 0.01573 & 0.43089 \\
\hline $\mathbf{P}_{\mathbf{t}-\mathbf{1}}$ & 01000000 & 0.21180 & 0.07832 & 0.84722 \\
\hline $\mathbf{Q}_{\mathbf{t}-\mathbf{1}}$ & 00001000 & 0.16597 & 0.02499 & 0.66391 \\
\hline $\mathbf{Q}_{\mathbf{t}-\mathbf{2}}$ & 00000100 & 0.23816 & 0.05451 & 0.95264 \\
\hline $\mathbf{P}_{\mathbf{t}} \mathbf{Q}_{\mathbf{t}}$ & 10010000 & 0.06282 & 0.01161 & 0.25129 \\
\hline $\mathbf{P}_{\mathbf{t}-\mathbf{1}} \mathbf{Q}_{\mathbf{t}}$ & 01010000 & 0.09455 & 0.02161 & 0.37822 \\
\hline $\mathbf{P}_{\mathbf{t}, \mathbf{Q}} \mathbf{t}$ & 10001000 & 0.07827 & 0.01164 & 0.31311 \\
\hline $\mathbf{P}_{\mathbf{t}-\mathbf{1}} \mathbf{Q}_{\mathbf{t}-\mathbf{1}}$ & 01001000 & 0.15294 & 0.02497 & 0.61176 \\
\hline $\mathbf{P}_{\mathbf{t}} \mathbf{Q}_{\mathbf{t}-\mathbf{2}}$ & 10000100 & 0.09797 & 0.01098 & 0.39188 \\
\hline $\mathbf{P}_{\mathbf{t}-\mathbf{1}} \mathbf{Q}_{\mathbf{t}-\mathbf{2}}$ & 01000100 & 0.20847 & 0.03638 & 0.83391 \\
\hline
\end{tabular}

Table.3 Fuzzy rules relating rainfall and streamflow to sediment concentration

\begin{tabular}{|c|c|c|c|c|}
\hline & Rainfall & Streamflow & & Sediment load \\
\hline IF & L & L & THEN & EL \\
\hline IF & L & M & THEN & VL \\
\hline IF & L & H & THEN & VL \\
\hline IF & L & VH & THEN & VL \\
\hline IF & L & EH & THEN & VL \\
\hline IF & M & VL & THEN & EL \\
\hline IF & M & L & THEN & VL \\
\hline IF & M & M & THEN & L \\
\hline IF & M & H & THEN & QL \\
\hline IF & M & VH & THEN & THEN \\
\hline IF & M & EH & M \\
\hline IF & M & L & THEN & QL \\
\hline IF & M & M & THEN & QH \\
\hline IF & M & H & THEN & H \\
\hline IF & M & VH & THEN & VH \\
\hline IF & H & EH & THEN & VL \\
\hline IF & H & VL & THEN & QL \\
\hline IF & H & L & THEN & QH \\
\hline IF & H & M & THEN & H \\
\hline
\end{tabular}

(Exceptional Low=EL; Very Low=VL; Low=L; Quite Low=QL; Medium=M; Quite High=QH; High=H; Very High=VH; Exceptional High=EH) 
Table.4 Model performance statistics during testing period for the architecture $2 * 2$

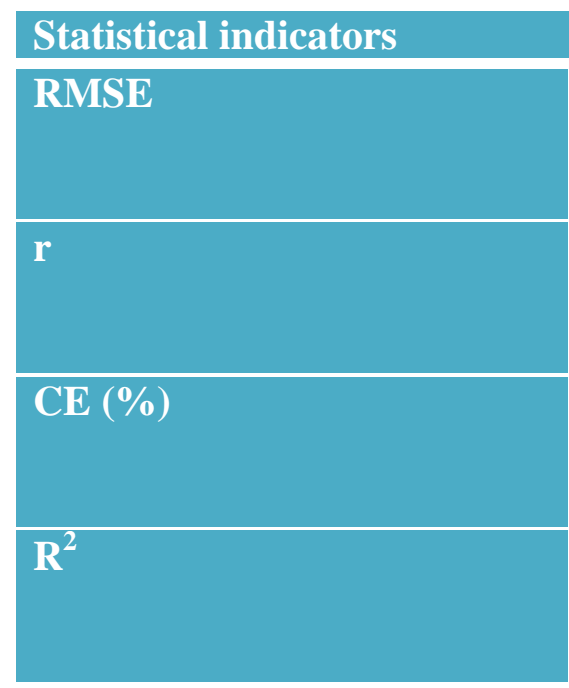

\begin{tabular}{|c|c|}
\hline Model & Architecture $(2 * 2)$ \\
\hline FL & 109.407 \\
\hline MLR & 226.339 \\
\hline SRC & 233.899 \\
\hline FL & 0.954 \\
\hline MLR & 0.801 \\
\hline SRC & 0.673 \\
\hline FL & 87.576 \\
\hline MLR & 46.828 \\
\hline SRC & 43.216 \\
\hline FL & 0.910 \\
\hline MLR & 0.642 \\
\hline SRC & 0.453 \\
\hline
\end{tabular}

Table.5 Model performance statistics during testing period for the architecture $3 * 1$

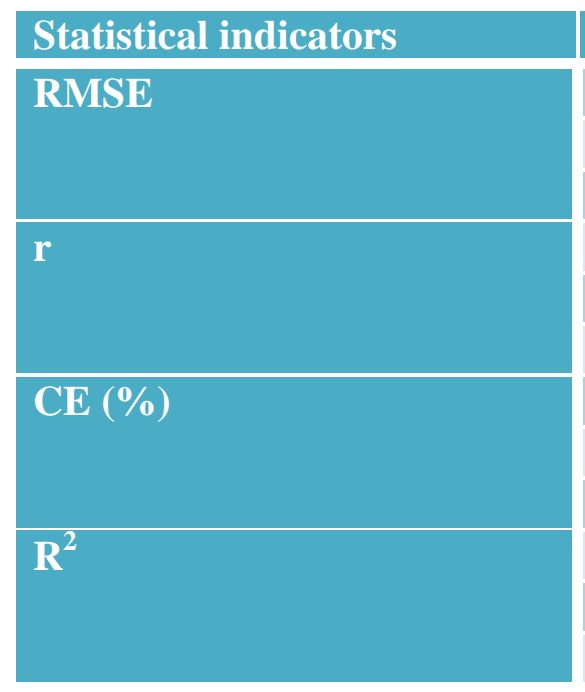

\begin{tabular}{|c|c|}
\hline Model & Architecture $\left(3^{*} \mathbf{1}\right)$ \\
\hline FL & 104.852 \\
\hline MLR & 180.344 \\
\hline SRC & 192.464 \\
\hline FL & 0.963 \\
\hline MLR & 0.872 \\
\hline SRC & 0.828 \\
\hline FL & 87.932 \\
\hline MLR & 64.300 \\
\hline SRC & 59.340 \\
\hline FL & 0.927 \\
\hline MLR & 0.761 \\
\hline SRC & 0.686 \\
\hline
\end{tabular}

Table.6 Comparison among the FL, MLR and SRC models

\begin{tabular}{|l|c|c|c|c|c|c|}
\hline \multirow{2}{*}{ Model } & \multicolumn{3}{|c|}{ Architecture (2*2) } & \multicolumn{3}{c|}{ Architecture (3*1) } \\
\cline { 2 - 8 } & RMSE & r & CE & RMSE & r & CE \\
\hline FL & 109.407 & 0.954 & 87.576 & 104.852 & 0.963 & 87.932 \\
\hline MLR & 226.339 & 0.801 & 46.828 & 180.344 & 0.872 & 64.300 \\
\hline SRC & 233.899 & 0.673 & 43.216 & 192.464 & 0.828 & 59.340 \\
\hline
\end{tabular}

The developed models were subjected for qualitative and quantitative performance to assess the potential of models in simulation of actual circumstances. Based on the performance evaluation indices during testing period the following conclusions were drawn from the study. The fuzzy logic model with architecture $3 * 1$ outperformed the FL, MLR 
and SRC models for estimating suspended sediment load for the given study watershed.

Three years of training arrangement performed better than two years of training arrangement for daily suspended sediment estimation.

Fuzzy logic model had the best accuracy in total sediment load estimation.

Results shown by MLR models were less satisfactory.

SRC model fits poorly for the data set under study.

It can be concluded that the soft computing techniques are more adequate in view of complexity and importance of the suspended sediment concentration problems.

\section{Acknowledgement}

The authors thank to India Meteorological Department (IMD) and Central Water Commission (CWC), Godavari Mahanadi Circle Division, South Eastern Region, Bhubaneswar, Orissa for the data used in the study and are also grateful to Dr. Anil Kumar Lohani, Scientist-G, National Institute of Hydrology, Roorkee, Uttarakhand, India for timely help, motivation and valuable suggestions.

\section{References}

Akhbari, M., Grigg NS. 2013. A framework for an agent-based model to manage water resources conflicts. Water Resour Manag 27: 4039-4052.

Ardiclioglu, M., Kisi, O., Haktanir, T. 2007. Suspended sediment prediction by using two different feed-forward back propagation algorithms. Canadian Journal of Civil Engineering 34(1): 120-
125.

Bae, D.H., Jeong, D.M., Kim, G. 2007. Monthly dam inflow forecasts using weather forecasting information and neuro-fuzzy technique. Hydrological Science Journal 52(1): 99-113.

Bilgili, M. 2010. Prediction of soil temperature using regression and artificial neural network models. Meteorology and Atmospheric Physics 110: 59-70.

Brevik, E.C., Cerda, A., Mataix-Solera, J., Pereg, L., Quinto, J.N., Six, J., Van Oost, K. 2015. The interdisciplinary nature of Soil. Soil, 1: 117-129.

Burger, C.M., Kolditz, O., Fowler, H.J., Blenkinsop, S. 2007. Future climate scenarios and rainfall-runoff modeling in the upper Gallego Catchment (Spain). Environ Pollut 148:842-854.

Chang, C.K, Ghani, A.A., Abdullah, R., Zakaria, N.A. 2008. Sediment transport modeling for Kulim River case study. Journal of Hydro-environment Research 2(1): 47-59.

Chang, F.J., Chen, Y.C. 2001. A counter propagation fuzzy-neural network modeling approaches to real time streamflow prediction. Journal of Hydrology 245: 153-164.

Chang, F.J., Hu, H.F., Chen, Y.C. 2001. Counter propagation fuzzy-neural network for streamflow reconstruction. Hydrological Processes 15(2): 219-323.

Cigizoglu, H.K. 2003. Estimation, forecasting and extrapolation of river flows by artificial neural networks. Hydrological Science Journal 48(3): 349-361.

Cigizoglu, H.K., Kisi, O. 2006. Methods to improve the neural-network performance in suspended sediment estimation. Journal of Hydrology 317: 221-238.

Clark, E. H., Haverkamp, J. A. \& Chapman, W. 1985. Eroding soils-the off-farm impacts. The conservation Foundation 
Report, 252-253. Washington DC, USA.

Daily, G., Dasgupta, P., Bolin, B., Crosson, P., Folke, C., Jansson, A. M., Jansson, B. O., Kautsy, N., Kingzig, A., Levin, S., Maler, K. G., Pinstrup-Andersen, P., Siniscalco, D. and Walker, B. 1998. Food production, Population growth, and the environment. Science 281: 1291-1292.

Decock. C., Lee, J., Necpalova, M., Pereira, E.I.P., Tendall, D.M., Six, J. 2015. Mitigating N2O emissions from soil: from patching leaks to transformative action. Soil 1: 687-694.

Engeland, K. and Hisdal, H. 2009. A comparison of low flow estimates in ungauged catchments using regional regression and the HBV-model. Water Resources Management 23(12): 25672586.

Eslamian, S.S., Ghasemizadeh, M., Biabanaki, M., Talebizadeh, M. 2010. A principal component regression method for estimating low flow index. Water Resources Management 24(11): 25532566.

FAO, 2015.

Giustolisi, O., Lauchelli, D. 2005. Improving generalization of artificial neural networks in rainfall-runoff modeling. Hydrological Science Journal 50(3): 515-528.

Gregory, K.J., Walling, D.E. 1973. Drainage basin form and processes: A Geomorphological Approach. Halsted (Wiley), New York, 456p.

Holeman, J.N. 1968. The Sediment Yield of Major Rivers of the World. Water Resources Research 4: 4.

Hundecha, Y., Bardossy, A., Theissen, H.W. 2001. Development of a fuzzy logicbased rainfall-runoff model. Hydrological Science Journal 46(3): 363-376.

ICAR and NAAS. 2010. Degraded and
Wastelands of India: Status and spatial distribution. Indian Council of Agricultural Research, New Delhi, India, $158 \mathrm{p}$.

Jayewardene, A.W., Xu, P.C., Tsang, F., Li, W.K. 2006. Determining the structure of a radial basis function network for prediction of nonlinear hydrological time-series. Hydrological Sciences Journal 51(1): 21-44.

Keesstra, S.D., Bouma, J., Wallinga, J., Tittonell, P., Smith, P., Cerda, A., Luca, M., Quinton, J., Pachepsky, P., Van der putten, W.H., Bardgett, R.D., Moolenaar, S., Mol, G., Jansen, B., Fresco, O.L. 2016. Soil 2: 11-128.

Kisi O. 2016. A new approach for modeling suspended sediment: Evolutionary fuzzy approach. Hydrology and Earth System Sciences.

Kisi, O. 2004a. River flow modeling using artificial neural networks. Journal of Hydrologic Engineering 9(1): 60-63.

Kisi, O. 2007. River flow forecasting using different artificial neural network algorithms. Journal of Hydrologic Engineering 12(5): 532-539.

Kisi, O. 2008a. River flow forecasting and estimation using different artificial neural network techniques. Hydra. Res. 39(1): 27-40.

Kisi, O., Cobaner, M., 2009. Modelling riverstage discharge relationship using different neural networks. Clean-Soil, Air, Water 37(2): 160-169.

Lal, R. 1995. Erosion crop productivity relationships for soils of Africa. J. Soil Science Soc. Am. 59: 661-667.

Lohani, A.K, Goel, N.K., Bhatia, K.K.S. 2006. Takagi-Sugeno fuzzy inference system for modeling stage-discharge relationship. Journal of Hydrology 331(1-2): 146-160.

Marofi, S., Tabari, H., Zare, A.H. 2011. Predicting spatial distribution of snow water equivalent using multivariate non- 
linear regression and computational intelligence methods. Water Resources Management 25: 1417-1435.

Matson, P. A., Parton, W. J., Power, A. G. \& Swift, M. J. 1997. Agricultural intensification and ecosystem properties. Science, 277: 504-509.

Nayak, P.C., Sudheer, K.P., Ramasastri, K.S. 2004. A neuro-fuzzy computing technique for modeling hydrological time series. Journal of Hydrology 291: 52-66.

Nayak, P.C., Sudheer, K.P., Ramasastri, K.S. 2005. Fuzzy computing based rainfallrunoff model for real time flood forecasting. Hydrological Processes 19: 955-968.

Nayak, P.C., Sudheer, K.P., Ramasastri, K.S. 2005. Short-term flood forecasting with a neuro-fuzzy model. Water Resources Management 41: 2517-2530.

Oinam, B.C., Marx, W., Scholten, T., Wieprecht, S. 2014. Fuzzy rule base approach for developing soil a protection index map: a case study in the upper Awash basin, Ethopian highlands. Land Degradation and Development 25(5): 483-500.

Pandey, A., Chowdary, V.M., Mal, B.C., Bilib, M. 2008. Runoff and sediment yield modeling from a agriculture watershed in India using the WEPP model. J Hydrol 348:305-319.

Pimentel, D., Havery, C., Resosudarmamo, P., Sinclair, K., Kurz, D., McNair, M., Crist, S., Shpritz, L., Fitton, L., Saffouri, R. and Blair, R. 1995. Environmental and economic costs of soil erosion and conservation benefits. Science 267: 1117-1123.

Ray, D.K., Muller, N.D., West, P.C., Foley, J.A., 2013. Yield trends are insufficient to double global crop production by 2050. PloS ONE 8, http://dx.doi.org/10.1371/journal.pone.0 066428.
Reddy, M.S., 1999. Theme paper on "Water: Vision 2050". Indian Water Resources Soc. Roorkee, pp. 51-53

Sadeghi, S.H.R., Seghaleh, M.B., Rangaver, A.S. 2013. Plot sizes dependency of runoff and sediment yield estimates from small watersheds. Catena 102: 5561.

See, L. Openshaw, S. 2000. Applying soft computing approaches to river level forecasting. Hydrological Sciences Journal 44(5): 763-779.

Sehgal, J.1., Abrol, I.P. 1994. Soil degradation in India: status and impact. Oxford and IBH Publishing Company Pvt. Ltd., New Delhi, India, 80 pp.

Stuber, M., Gemmar, P., Greving, M. 2000. Machine supported development of fuzzy-flood forecast systems. In: European Conf. on Adv. In Flood Res. (Potsdam, Germany) (ed. By A. Bronstert, C. Bismuth and L. Menzel), 504-515.

Tabari, H., Marofi, S., Zare, A.H., Sharifi, M.R. 2010. Comparison of artificial neural network and combined models in estimating spatial distribution of snow depth and snow water equivalent in samsami basin of iran. Neural Computing Application 19: 625-635.

Tallis JH. 1998. Growth and Degradation of British and Irish Blanket mires. Environmental Reviews 6(2): 81-122.

Tayfur, G. 2002. Artificial neural networks for sheet sediment transport. Hydrological Science Journal 47(6): 879-892.

Tayfur, G., Ozdemir, Singh, V.P. 2003. Fuzzy logic algorithm for runoff-induced sediment transport from bare soil surfaces. Advances in Water Resources, 26: 1249-1256.

Vercruysse, K., Robert, C.G., Rickson, R.J. 2017. Suspended sediment transport dynamics in rivers: Multi-scale driver of temporal variation. Earth-Science 
Reviews.

Verma, A.K., Jha, M.K., and Mahana, R.K. 2010. Evaluation of HEC-HMS and WEPP for simulating watershed runoff using remote sensing and geographical information system. Paddy Water Environ, 8:131-144.

Verstraeten, G., Poesen, J. 2001. Factors controlling sediment transport from small intensively cultivated catchment in a temperate humid climate. Geomorphology 40(1-2), 123-144.

Wang, J., Ge, J., Hu, Y., Li, C., Wang, L. 2015. Fuzzy intelligence system for land consolidation-a case study for Shunde, China. Soil Earth 6: 997-1006.

Wang, P., Linker, L.C. 2008. Improvement of regression simulation in fluvial sediment loads. J. Hydra. Eng. 134: 1527-1531.

White, S. 2005. Sediment yield prediction and modelling. Hydrological Processes 19: 3053-3057.

Xiong, L.H., Shamsaldein, A.Y., O'Connor, K.M. 2001. A nonlinear combination of the forecasts of rainfall-runoff models by the first order Takagi-Sugeno fuzzy system. Journal of Hydrology 245: 196217.

Yang, C.T. 1996. Sediment transport theory and practice, McGraw-Hill, New York.

Zhu, M.L, Fujita, M., Hashimoto, N., Kudo, M. 1994. Long lead time forecast of runoff using fuzzy reasoning method. J. Japan. Soc. Hydrology and Water Resources 7(2): 83-89.

Zounemat-Kermani, M., Teshnehlab, M. 2008. Using adaptive neuro-fuzzy inference system for hydrological time series prediction. Applied Soft Computing 8: 928-36.

\section{How to cite this article:}

Shreya Nivesh, Pravendra Kumar, Pragati Sawant and Ramesh Verma. 2018. Application of Fuzzy Logic and Statistical Approaches for Estimation of Suspended Sediment Concentration. Int.J.Curr.Microbiol.App.Sci. 7(02): 3716-3733. doi: https://doi.org/10.20546/ijcmas.2018.702.441 